\title{
APONTAMENTOS SOBRE RAÇA, IDENTIDADES E ENUNCIAÇÃO DA DIFERENÇA
}

\author{
NOTES ABOUT RACE, IDENTITIES AND DISCUSSION OF \\ DIFFERENCE
}

\section{NOTAS SOBRE RAZA, IDENTIDADES Y ENUNCIACIÓN DE LA DIFERENCIA}

\author{
Wilson Rogério Penteado Júnior ${ }^{1}$
}

\begin{abstract}
RESUMO:
O presente ensaio busca articular a discussão sobre identidade e a noção de raça, investindo na compreensão da complexidade desses termos quando colocados em relação. Se, como se sabe, a raça não pode ser entendida como um dado explicativo da natureza, sendo, portanto, um construto social, há que se pensar sobre ele. $O$ que fazer com a noção de raça, mola propulsora do racismo, tão fortemente enfatizada pelos sujeitos sociais concretos? Evidentemente, esta não é uma questão que suporte resposta imediata e nem este ensaio como nenhum outro - teria como dar conta de questão de tamanha envergadura. No entanto, fazer apontamentos e recuperar aspectos importantes em torno da questão é um exercício sobre o qual devemos nos debruçar, ainda que a título de convite para reflexão. Admitindo as armadilhas e limites oferecidos pela noção de raça no jogo das relações de alteridade, este ensaio propõe que se pense a questão em termos de enunciação da diferença, entendendo o dilema das identidades enquanto processo político gerado em repertórios de poder.
\end{abstract}

Palavras-chave: Identidades. Raça. Enunciação da diferença.

\footnotetext{
${ }^{1}$ Doutor em Antropologia Social - UNICAMP, Professor Associado de Antropologia, na Universidade Federal do Recôncavo da Bahia - UFRB. E-mail: penteadowji@ ufrb.edu.br
} 


\section{ABSTRACT:}

This essay seeks to articulate the discussion on identity and the notion of race, investing in the understanding of the complexity of terms when put in relation. If, as is known, race cannot be understood as an explanatory data of nature, being, therefore, a social construct, it is necessary to think about it. What to do with a notion of race, the driving force behind racism, so strongly emphasized by concrete social subjects? Evidently, this is not a question that supports an immediate answer, nor would this essay - like any other - be able to deal with such a large issue. However, making notes and recovering important aspects around the issue is an exercise that we must dedicate ourselves, we must dedicate ourselves, even if only for reflection. Admitting the pitfalls and limits offered by the notion of race in the game of alterity relations, this essay proposes to think the issue in terms of enunciation of difference, understanding the dilemma of identities as a political process generated in power repertoires.

Keywords: Identities. Race. Enunciation of difference.

\section{RESUMEN:}

Este ensayo busca articular la discusión sobre la identidad y la noción de raza, enfocado en comprender la complejidad de estos términos cuando se colocan en relación. Si, como se sabe, la raza no puede entenderse como un dato explicativo de la naturaleza, siendo, por tanto, un constructo social, es necesario pensar en ello. ¿Qué hacer con la noción de raza, motor del racismo, tan enfatizada por sujetos sociales concretos? Evidentemente, esta no es una pregunta que respalde una respuesta inmediata, ni este ensayo, como cualquier otro, podría abordar un tema tan grande. Sin embargo, tomar notas y recuperar aspectos importantes en torno al tema es un ejercicio que debemos abordar, aunque sea como una invitación a la reflexión. Admitiendo las trampas y límites que ofrece la noción de raza en el juego de las relaciones de alteridad, este ensayo propone pensar el tema en términos de enunciación de la diferencia, entendiendo el dilema de las identidades como un proceso político generado en repertorios de poder.

Palabras clave: Identidades. Raza. Enunciación de la diferencia.

Como bem argumenta o eminente antropólogo brasileiro-congolês Kabengele Munanga (2003), apesar de a raça não existir biologicamente ${ }^{2}$, "isto é insuficiente para fazer

\footnotetext{
${ }^{2}$ Para uma discussão sobre a emergência da noção de raça e suas implicações ver Munanga (2003). Reproduzo aqui, no entanto, trecho de seu texto que contribui sumariamente para o entendimento da questão: "No século XX [...] O cruzamento de todos os critérios possíveis (o critério da cor da pele, os critérios morfológicos e químicos) deu origem a dezenas de raças, sub-raças e sub-sub-raças. As pesquisas comparativas levaram [...] à conclusão de que os patrimônios genéticos de dois indivíduos pertencentes a uma mesma raça podem ser mais distantes que os pertencentes a raças diferentes; um marcador genético característico de uma raça, pode, embora com menos incidência ser encontrado em outra raça. [...] Combinando todos esses desencontros com os Revista Educação e Ciências Sociais, Salvador, v.3, n.5, 2020.
} 
desaparecer as categorias mentais que a sustentam. O difícil é aniquilar as raças fictícias que rondam em nossas representações e imaginários coletivos" (MUNANGA, 2003, s/p). Ainda de acordo com o citado autor, o problema que envolve a raça - a despeito de sua inexistência científica e inoperacionalidade enquanto conceito - consiste no fato de ser uma categoria social de dominação e de exclusão (ibidem).

Partindo disso é que se busca teorizar neste ensaio sobre a noção de raça nas questões que envolvem o tema das identidades, pois, como é sabido, não se pode tomar a identidade enquanto substância, algo anteposto, uma entidade palpável e definida, mas sim como um construto - não apenas enquanto categoria analítica confinada ao meio acadêmico, mas enquanto ideia que ganha força e legitimidade em contextos sociais concretos, disseminada nas diversas relações de poder entre grupos sociais. E como pensar, diante disso, a questão identitária em sua interface com a noção de raça?

Tomada em seu aspecto sociológico, a noção de raça no campo de produção acadêmica contou logo com noções correlatas, tais como identidade e etnia. Isto se deu de modo tão substantivo que muitas vezes raça e etnia, atravessadas pelo conceito de identidade, tendem a ser utilizadas como equivalentes. Munanga (2003) apontando para tal fenômeno adverte que:

Tanto o conceito de raça quanto o de etnia são hoje ideologicamente manipulados. É esse duplo uso que cria confusão na mente dos jovens pesquisadores ou iniciantes. A confusão está justamente no uso não claramente definido dos conceitos de raça e etnia que se refletem bem nas expressões tais como as de "identidade racial negra", "identidade étnica negra", "identidade étnico-racial negra", etc. (MUNANGA, 2003, s/p).

Tal "confusão" - termo empregado aqui muito mais no sentido de estado do que é ou se encontra confundido, misturado - tem, por certo, sua marca na história do conhecimento sociológico, quando, mesmo a despeito da persistência da noção de raça, diversos estudiosos buscavam se apegar ao conceito de etnia, justamente como forma de se evitar conotações de

progressos realizados na própria ciência biológica (genética humana, biologia molecular, bioquímica), os estudiosos desse campo de conhecimento chegaram à conclusão de que a raça não é uma realidade biológica, mas sim apenas um conceito alias cientificamente inoperante para explicar a diversidade humana e para dividila em raças estancas. Ou seja, biológica e cientificamente, as raças não existem” (MUNANGA, 2003, s/p). 
cunho centralmente biológico para explicação das diferenças entre grupos humanos. $\mathrm{O}$ texto que se sagrou clássico, "Relações Comunitárias Étnicas", escrito pelo sociólogo alemão Max Weber no início do século XX, cumpriu um papel seminal nesse tocante e muitos outros textos inspirados no conceito de etnia se seguiram depois dele.

Nesse quadro, a antropologia se colocou como um dos campos do conhecimento que mais se dedicou ao estudo das identidades étnicas, vistas precipuamente em seu viés coletivo. Assim, o conceito de identidade passou a ser cada vez mais trabalhado por antropólogos e sociólogos, com o intuito de se compreender "conflitos, relações desiguais entre grupos, classes e culturas, surtos de revolta de minorias sociais, de grupos étnicos, de povos colonizados, de classes oprimidas" (BRANDÃO, 1986:47). Nesse tocante, diversos autores cuidaram de bem desenhar os limites entre as análises preocupadas com uma dimensão individual e aquelas mais voltadas para uma dimensão coletiva no tema das identidades (BRANDÃO, 1986; CARDOSO DE OLIVEIRA, 1975; HALL, 1995 e 1997).

Se o citado estudo de Max Weber cumpriu papel seminal quanto à discussão sobre identidade étnica, não há dúvidas de que os escritos do antropólogo norueguês Fredrik Barth, especialmente seu, hoje clássico, Ethnic Groups and Boundaries: the social organization of culture difference, publicado em 1969, cumpriu a tarefa de sistematização daquela discussão no meio acadêmico. Barth enxergou nos grupos étnicos uma forma de organização social baseada na identificação que seria constituída pela auto-atribuição e a atribuição pelo outro, via noção de fronteira.

Considerado uma das mais importantes referências nos estudos sobre etnicidade, esse autor parte do princípio de negação da noção de raça como prioridade para se pensar a identidade étnica, enfatizando a importância da conduta - para, então, demonstrar a dimensão das fronteiras nas relações étnicas. Se Max Weber falava em "hábitos", Barth enfatizou a importância das "normas de conduta" entre os grupos étnicos, entendendo que a delimitação da diferença se estabelece na fronteira, e não ao que há de supostamente intrínseco a um grupo. Seu argumento baseia-se, portanto, na ideia de interação étnica. Para ele, os grupos étnicos não são fechados, eles são abertos na relação com os outros. E é neste plano que a fronteira se constrói. Nesse sentido, o aspecto mais importante para Barth é a auto-atribuição dos sujeitos na interação étnica, sugerindo que se pense nos grupos étnicos através de suas fronteiras sociais. Empenha-se em desfazer, assim, a equação grupo étnico = cultura, pois para ele a consciência da diferença se dá no contato, tratando-se, portanto de uma consciência de 
dimensão política em que a identidade assume sua condição situacional. Podemos admitir, assim, que uma das principais contribuições de Barth para definir a identidade foi a constatação de que esta se exprime como um sistema de oposições ou contrastes e, por isso mesmo, é possível dizer que a identidade étnica é sempre contrastiva.

Alguns autores posteriores a ele criticaram suas formulações afirmando que o mesmo teria reduzido a identidade étnica a um sistema cultural encerrado entre fronteiras, ignorando as relações sociais existentes no interior dos próprios grupos etnicamente definidos. Por ter privilegiado o grupo étnico no limite de suas fronteiras organizacionais, Barth não teria dado a devida atenção à arena dos conflitos dentro dos próprios limites do grupo étnico ${ }^{3}$.

A teorização do tema da identidade baseou-se não apenas no trabalho pioneiro de Barth, mas também nas obras de outros autores como é o caso de Abner Cohen (1969).

Entre final dos anos de 1960 e início dos 1970, esse autor procurou demonstrar que os objetos tradicionais da antropologia ("tribos", "vilas", "comunidades isoladas") estavam sendo transformados em "grupos étnicos", que seriam também "grupos de interesse", já que fariam um uso instrumental (econômico e/ou político) da etnicidade. Para Cohen (1969), os grupos étnicos constituíam-se como fenômenos urbanos, perpassados também pelas disputas de classe.

Importante salientar que a referência a tais autores se apresenta aqui de um modo um tanto arbitrário, embora, não sem razão de ser. Evidentemente que os referidos trabalhos de Barth (1969) e Cohen (1969) não eram os únicos a figurar a questão das identidades étnicas no cenário acadêmico. Eles são evocados aqui, no entanto, pela repercussão que ganharam por uma série de razões que não cabe aqui explorar - e servem de bom exemplo de como nos meados do século XX a discussão sobre identidades e processos de etnicidade ganhava evidente importância no cenário acadêmico. Como bem aponta a cientista social brasileira, com carreira nos Estados Unidos, Patrícia Pinho (2004), há que se considerar que, antes mesmo do surgimento das proposições instauradas por Barth e Cohen, os elementos para a formação da teoria contemporânea de identidade já podiam ser percebidos no interior do campo teórico da antropologia em meados do século XIX, quando de suas origens

\footnotetext{
${ }^{3}$ Para Roberto Cardoso de Oliveira (1975), por exemplo, Barth privilegiou o nível das relações sociais ou da organização social como a base sobre a qual dever-se-ia inquirir o grupo étnico e sua identidade, o que teria sido uma deficiência em seu estudo, pois não deu a atenção devida às representações e ideologias engendradas nas relações interétnicas.
} 
institucionais. Morgan, ao conceituar o "período étnico", já lançava as sementes do estudo da etnicidade. A teoria da identidade, portanto, não representaria para as ciências sociais o surgimento de uma nova episteme ou um momento de ruptura epistemológica. Mais do que uma "descoberta" científica, a identidade enquanto teoria seria, para essa autora, o aprofundamento de uma percepção há muito iniciada.

Seja como for, a partir da década de 1970, as ciências sociais começam a privilegiar a ação dos (e entre os) grupos étnicos. Reconhecia-se, a partir dali, que as características étnicas, baseadas em distinções raciais, de línguas, sotaques, religiões, etc. eram agenciadas na arena do poder, da dominação, do estabelecimento e enfrentamento das desigualdades, passando a ser, portanto, valorizadas em seus aspectos políticos.

O contraste, como elemento fundamental para a construção das identidades, foi bastante valorizado, comprovando que alguns pontos descobertos pela teoria de Barth (1969) não deviam ser deixados de lado. Os destacados estudos, no Brasil, da antropóloga Manuela Carneiro da Cunha $(1985 ; 1986)$, sobre identidade e etnicidade, por exemplo, haviam ressaltado o papel da diferença como elemento fundador das identidades. Em seus textos, Carneiro da Cunha define que o conceito básico de identidade étnica é a formação de uma identidade construída de maneira situacional e contrastiva, articulada com outras identidades através de relações opositivas, compondo uma estratégia de diferenças (CARNEIRO DA CUNHA, 1985).

Roberto Cardoso de Oliveira já havia escrito que "quando uma pessoa ou um grupo se afirmam como tais, o fazem como meio de diferenciação em relação a alguma pessoa ou grupo com que se defrontam. É uma identidade que surge por oposição, isto é, ela não se afirma isoladamente" (CARDOSO DE OLIVEIRA, 1975, p.5).

Enquanto fenômeno relacional, a identidade está sempre em processo, gerando confrontos e enfrentamentos, por isso, é preciso sublinhar seu caráter processual, contrastivo e não substantivo. Podemos entender, então, que a identidade é mais que uma continuidade de um passado vivido; é um processo contínuo de construção de um consenso capaz de, em situações específicas, fornecer elementos para que componentes de um determinado grupo se reconheçam como iguais, e definir aqueles que estão localizados fora do grupo como diferentes. 
Não há dúvidas de que, enquanto conceito, a identidade tem tido um papel central em importantes questões teóricas e políticas. Nas sugestivas asserções feitas pelo historiador britânico Paul Gilroy (2000), a popularidade e aceitação do termo identidade, enquanto recurso interpretativo, é resultante, dentre outras coisas, da pluralidade de significados que o termo abrange. Seu uso na academia mistura-se com o uso feito pelo senso comum e cada vez mais se cristaliza a noção de que a identidade é sempre circunscrita e particular, servindo para reforçar os sentidos de nação, raça, etnia, especificidade cultural, regionalismo e localidade.

Diante disso, como podemos pensar as implicações da identidade atravessada pela noção de raça e seus dilemas? Em outros termos, como pensar o racismo e seus dilemas que, no limite, tem na ideia de raça seu substrato? Trazendo à discussão uma vez mais Kabengele Munanga (2003):

[...] com base nas relações entre "raça" e "racismo", o racismo seria teoricamente uma ideologia essencialista que postula a divisão da humanidade em grandes grupos chamados raças contrastadas que têm características físicas hereditárias comuns, sendo estas últimas suportes das características psicológicas, morais, intelectuais e estéticas e se situam numa escala de valores desiguais. Visto deste ponto de vista, o racismo é uma crença na existência das raças naturalmente hierarquizadas pela relação intrínseca entre o físico e o moral, o físico e o intelecto, o físico e o cultural. O racista cria a raça no sentido sociológico, ou seja, a raça no imaginário do racista não é exclusivamente um grupo definido pelos traços físicos. A raça na cabeça dele é um grupo social com traços culturais, linguísticos, religiosos, etc. que ele considera naturalmente inferiores ao grupo a qual ele pertence. De outro modo, o racismo é essa tendência que consiste em considerar que as características intelectuais e morais de um dado grupo, são consequências diretas de suas características físicas ou biológicas (MUNANGA, 2003, s/p).

Nesse sentido, a raça se coloca como categoria carregada de ideologia, pois como todas as ideologias, reserva sua dimensão não proclamada: a relação de poder e de dominação (ibidem).

Como bem observa a cientista política venezuelana, com carreira no Brasil, Johanna Monagreda (2017), fazendo coro com outros autores, não há dúvidas de que o racismo contribui para a naturalização das desigualdades sociais, em vários âmbitos. No entender da 
autora, ao ser socializada a noção de raça, "o racismo também se socializa e permanece introjetado no imaginário coletivo, funcionando ativamente no estabelecimento e reprodução de hierarquias grupais, bem como na manutenção de estruturas sociais, econômicas e políticas racializadas" (MONAGREDA, 2017, p.367).

Assim, a complexidade da questão que envolve o racismo pode ser atestada na própria persistência da noção de raça. Os dispositivos que operam a lógica racista conduzem inclusive oprimidos e subordinados a enfrentarem a opressão racial sem abrirem mão do termo raça, buscando se situarem reativamente dentro do mesmo repertório de poder que produziu o mal do qual sofrem, isto é, o racismo.

Em relação à situação dos segmentos negros e suas estratégias de sobrevivência diante das violências promovidas pelo fenômeno do racismo, vê-se que movimentos negros de diversas partes do mundo passaram a considerar o corpo negro como o locus da identidade e a arena de luta e contestação. Embora isso tenha possibilitado conquistas no plano da estética e da autoestima ${ }^{4}$ a esses segmentos, tal postura contribui, efetivamente, para reforçar a crença nos atributos naturais e a consequente postura de definir negritude a partir das características biológicas.

Vários pensadores apontaram para o lugar do corpo na afirmação das identidades dos segmentos negros. Para o sociólogo britânico-jamaicano Stuart Hall (1997; 1998), por exemplo, uma das características principais que torna as culturas negras "negras" é o uso estratégico do corpo como elemento central do capital cultural possuído pelos escravos, por seus descendentes e pelos destituídos de um modo geral. Para Gilroy (2000), as culturas negras definem-se, dentre outros fatores, por possuírem um pano de fundo comum de experiências que engloba uma memória da escravidão, um legado de africanismos e o efeito do racismo que é ditado pelos aspectos fenotípicos. As diferentes culturas que se formam no contexto negro diaspórico possuem suas próprias especificidades definidas de acordo com os contextos locais onde são produzidas, mas todas elas, segundo as observações oferecidas pelo autor, compartilham de algumas características comuns, como a crença em uma mesma

\footnotetext{
${ }^{4}$ Ver por exemplo os interessantes trabalhos etnográficos desenvolvidos por Antônio Risério (1981) e Patrícia Pinho (2004), que tratam da importância dada ao corpo pelos afrodescendentes em Salvador e à sua (re) significação nos blocos carnavalescos a exemplo do bloco "Filhos de Gandi", no caso do estudo de Risério (1981) e do "Ilê Aiyê", no caso do estudo de Pinho (2004).
}

Revista Educação e Ciências Sociais, Salvador, v.3, n.5, 2020. 
origem ou passado, a produção dos sentidos dados à África e a manipulação do corpo como locus de construção da negritude, para o qual a estética opera um papel fundamental.

Para Patrícia Pinho (2004), o problema maior não é o fato da bio-política contribuir para estetizar a política, mas é o fato de que ela serve para criar conexões políticas a partir do corpo, contribuindo para que a raça continue sendo um elemento divisor determinante da humanidade.

A esse respeito, se mostram pertinentes algumas observações feitas por Paul Gilroy (2000) em relação à importância que foi dada à cor da pele na lógica colonial. Fazendo referência ao pensador francês, nascido na Martinica, Frantz Fanon, Gilroy lembra que esse autor considerava o poder conferido à pele uma violação ao corpo humano em sua capacidade simétrica e subjetiva de humanidade. Sobre isso, comenta:

A concepção de Fanon fornece uma nota de rodapé interessante a toda a história das ciências raciais e às suas noções exclusivas de uma humanidade codificada pela cor. Quantas cores de pele existem? Como é possível, de maneira exata, científica, fazer com que as gradações de pele correspondam à variedade de 'raças'? (GILROY, 2000, p.47).

Fanon apontando para a necessidade de libertação da cor e da superação da raça, portanto, argumenta:

Na medida em que eu começo a reconhecer que o negro é um símbolo do pecado, eu me pego odiando o negro. Mas, então, eu reconheço que eu sou um negro. Há duas saídas para este conflito. Ou eu peço aos outros para não prestarem atenção à minha pele, ou então eu quero que eles a percebam. Eu procuro, então, achar um valor para aquilo que é ruim - já que eu tenho, inadiavelmente, concordado que o homem negro é a cor da maldade. A fim de interromper essa situação neurótica, na qual eu sou convencido a escolher uma solução doentia, conflituosa, alimentada por fantasias, hostil, em resumo, desumana, eu tenho apenas uma solução: erguer-me acima deste drama absurdo que os outros encenaram em mim, para rejeitar os dois termos, que são igualmente inaceitáveis e, através da minha humanidade, ir em busca do universal (FANON, 1991, p.197). 
Fanon já alertava, ainda nos anos de 1950, sobre a necessidade de libertar os negros dos seus arquétipos. Exigir que o negro corresponda aos arquétipos é o mesmo que mantê-lo escravo de uma essência e de uma aparência comprometida com a própria lógica colonial. Como bem aponta Monagreda (2017), inspirada na historiadora norte-americana Joan Scott (2005), “certas características grupais parecem adquirir uma relevância inusitada em determinados contextos políticos que fazem com que estas surjam e se destaquem como realidades sociais" (MONAGREDA, 2017, p. 384). Para autora, este seria, por exemplo, o caso "[...] quando a raça é construída para a dominação ou quando a ideia de raça é reclamada pelos mesmos estigmatizados, oprimidos e excluídos com a tentativa de se reconstruir um potencial emancipatório para estes grupos" (Ibidem, p. 384).

As observações críticas levantadas pelos diversos autores aqui mencionados em relação à estreita noção de raça contribuem para desafiar as noções estáticas de identidade e ampliar as possibilidades de construção dos sujeitos e o alcance da ação (agency) negra ${ }^{5}$.

Ato contínuo, a referência a outro autor se insinua sugestiva, no sentido de aprimorar o debate: o filósofo anglo-ganês Antony Kwame Appiah. Analisando o essencialismo presente nos discursos étnicos, Appiah (1997) busca diferenciar racialismo de racismo partindo da premissa de que não há raça, e sim o discurso sobre raça. $\mathrm{O}$ racialismo para esse autor é a visão existente na humanidade de "características hereditárias", que permite a divisão de grupos em termos raciais de modo que os membros de um dado grupo compartilham entre si certos traços e tendências que lhes seriam comuns, nada tendo a ver com membros de outros grupos. Traços e “... tendências características de uma 'raça' que constituiriam uma espécie de essência racial" (APPIAH, 1997, p.33). A diferença básica entre racismo e racialismo é que o racismo faria uso da noção de raça para fazer mal a determinados seres humanos, enquanto que o racialismo geralmente é utilizado como componente de discursos de formação e afirmação de identidades de grupos socialmente desfavorecidos.

Definindo identidade como "uma coalescência de estilos, de conduta, hábitos de pensamento e padrões de avaliação mutuamente correspondentes (ainda que às vezes

\footnotetext{
${ }^{5}$ A chamada ação (agency) negra é entendida como a capacidade de organização das comunidades da diáspora africana para interferir na ordem vigente e transformar o estado das coisas com base em elementos referenciados à concepção de cultura negra.
}

Revista Educação e Ciências Sociais, Salvador, v.3, n.5, 2020. 
conflitantes)", esse autor afirma que toda identidade humana é construída e histórica. A seu ver, histórias inventadas, biologias inventadas e afinidades culturais inventadas vêm junto com toda identidade; cada qual tem um papel que precisa ser roteirizado, estruturado pelas convenções de uma narrativa a que o mundo jamais consegue conformar-se realmente. Nesse sentido, não se pode, no seu entender, perder de vista a obviedade muitas vezes esquecida de que não existe um mundo "em si”, independente, desconectado do discurso e das representações. As representações constituem o mundo no qual vivemos, e são usadas pelas pessoas para conceitualizar o mundo, a si mesmas e aos outros.

Fanon demonstrou que o imperialismo europeu havia privado os sujeitos coloniais de sua humanidade e que, pior do que isso, cometeu o crime de quebrar a característica unitária da humanidade enquanto espécie. Segundo Patrícia Pinho (2004), Azevedo (2004), Gilroy (2000) dentre outros, é necessário resgatar o sentido de humanidade, reconhecer a força subversiva poderosa existente na idéia de "humanismo planetário" (GILROY, 2000), que significa renunciar conscientemente à noção de raça, subvertendo uma ordem opressora que foi imposta pelos colonizadores e que serviu para categorizar e dividir a humanidade.

A libertação de toda e qualquer forma de pensamento racializado e racialista de concepção do mundo, de si mesmo e dos outros representa a base para a fundação daquilo que Gilroy chamou de "humanismo planetário", enfatizando a necessidade de se abandonar a noção do corpo como repositório de uma noção limitada e congelada de cultura e de uma suposta "verdade racial".

Os teóricos adeptos da ideia de diáspora negra souberam, com bastante astúcia, identificar que é preciso se libertar da noção da raça, já que se trata de um construto social, fruto das relações colonialistas. Ao mesmo tempo, tem-se consciência de que não se trata de um empreendimento fácil. Pois, como bem observa Kabengele Munanga (2003), “A consciência política reivindicativa das vítimas do racismo nas sociedades contemporâneas está cada vez mais crescente, o que comprova que as práticas racistas ainda não recuaram" (MUNANGA, 2003, s/p). E, evidentemente, tal consciência política se desenvolve em conformidade com um repertório discursivo ancorado na ideia central de raça.

O antropólogo norte-americano Vincent Crapanzano (2002) observa que por mais crítica que seja nossa visão das categorias de racismo, por mais que nos distanciemos delas, inevitavelmente a reforçamos quando as discutimos e analisamos. Diante dessa observação, esse autor se pergunta sobre a real necessidade de começarmos nossos estudos sempre com os 
atores - os intérpretes - bem definidos em termos de raça, classe, gênero e etnicidade. Propõe que, talvez, seja mais proveitoso começar de modo mais impessoal, com compromissos e confrontações interpretativas no intuito de determinar as condições pragmáticas por meio das quais essas próprias categorias são definidas e aplicadas. Ou seja: descobrir a maneira como "raça", "classe", "gênero" e "etnicidade" emergem dessas confrontações interpretativas e como funcionam retórica e politicamente.

Enquanto acadêmicos, talvez um modo de contribuirmos, através de nossos estudos, com as críticas sobre a ideia reificada de raça seja, de fato, nos atermos aos enunciados políticos constituintes da diferença. O termo diferença é empregado aqui no sentido proposto pelo pensador indo-britânico Homi Bhabha (1998), isto é, como processo de enunciação da cultura como conhecível. Assim sendo, deve-se preocupar onde é que as diferenças são enunciadas. É nesse sentido que a própria noção de identidade só pode ser entendida a partir de seu enunciado. Sobre isso, a lição colocada por Stuart Hall parece fazer todo sentido ao questionar sobre quem precisa de identidade (HALL, 2003), se ela é afirmada (e se sim, quando é afirmada) e como e por que é afirmada? Pois, como bem adverte Joan Scott (2005), as identidades não são entidades eternas, e, sim, efeitos de processos políticos e sociais, “[...] um processo complexo e contingente suscetível a transformações” (SCOTT, 2005, p.29).

Sendo a raça, como dissemos, uma noção persistente no âmbito das relações sociais, há que nos perguntarmos sobre seu lugar na realidade vivida, radicalizando sua condição socialmente construída, pois se se trata de um construto, é preciso pensar sobre ele; de que construto estamos falando? Em que contextos específicos ele emerge? Sob quais propósitos e alegações?

Por certo, Appiah (1997), foi um dos pensadores que apresentou importante avanço nessa direção ao se colocar a questão: quando é que raça constitui pessoas? ${ }^{6}$ Tal questão se faz extremamente importante no sentido de não se fazer da noção de raça algo substancial ou mesmo não digno de reflexão. É preciso refletir sobre o que se está entendendo por raça nos processos específicos de enunciação da diferença, exatamente para não a reificar.

\footnotetext{
${ }^{6}$ Importante lembrar que Appiah (1997) está pensando nos termos da "pós-modernidade" no sentido de que as identidades são fragmentadas. Seu objetivo é mostrar que a raça não existe, que é possível uma identidade africana fugindo dos alicerces conceituais ocidentais e que muitos daqueles que um dia procuraram fugir desses conceitos acabaram reforçando-os.
}

Revista Educação e Ciências Sociais, Salvador, v.3, n.5, 2020. 
O que estamos entendendo por raça tal como proferida pelo discurso êmico? Às ciências sociais, bem como a áreas afins, cabe a tarefa de entender, desnaturalizar e, sobretudo, não negligenciar sua noção. Certamente, não se deve negligenciar o discurso enunciado da raça, desconciderando-o, e no limite, tratando com certa ressalva entre "aspas" como se se tratasse de um conceito que não merecesse reflexões mais aprofundadas. É preciso então, entender sua significação a partir destes mesmos contextos em que surge como discurso. Não para reforçá-lo, evidentemente, mas para compreendê-lo analítica e criticamente, com vistas a superá-lo.

Justamente porque as identidades não são coisas, mas processos que estão sob constante renegociação, é preciso desafiar a reificação e a essencialização das identidades e renunciar à ideia de que um dado grupo, ou segmento social, teria uma identidade básica caracterizada a partir de uma essência definidora. Dessa forma, a identidade deixa de ser vista como algo fechado que os grupos carregam e que estaria automaticamente conectada ao corpo, passando a ser vista como algo que é produzido social e historicamente.

\section{BIBLIOGRAFIA}

APPIAH, Kwame Anthony. Na Casa de Meu Pai: a África na filosofia da cultura. Rio de Janeiro: Contraponto, 1997.

AZEVEDO, Célia Maria Marinho de. "Prefácio". In: PINHO, Patrícia de Santana. Reinvenções da África na Bahia. São Paulo: Annablume, 2004.

BARTH, Fredrik. "Os Grupos Étnicos e suas Fronteiras". In: POUTIGNAT, Philippe. \& STREIFF-FENART, Jocelyne. Teorias da Etnicidade: seguido de Grupos Étnicos e suas Fronteiras de Fredrik Barth. São Paulo: Fundação Editora da Unesp, 1998.

BHABHA, Homi. "O Compromisso com a Teoria" e "Interrogando a Identidade: Franz Fanon e a Prerrogativa Pós-Colonial”. In: O Local da Cultura. Belo Horizonte: Editora da UFMG, 1998.

BRANDÃO, Carlos Rodrigues. Identidade e Etnia: construção da pessoa e resistência cultural. São Paulo: Brasiliense, 1986.

CARDOSO DE OLIVEIRA, Roberto. Identidade, Etnia e Estrutura Social. São Paulo: Livraria Pioneira Editora, 1975. 
CARNEIRO DA CUNHA, Manuela. Negros Estrangeiros: os escravos libertos e sua volta à África. São Paulo: Brasiliense, 1985.

CARNEIRO DA CUNHA, Manuela. Antropologia do Brasil: mito, história, etnicidade. São Paulo: Brasiliense/ EDUSP, 1986.

COHEN, Abner. Custom and Politics in Urban Africa: a study of Hausa migrants in Yoruba towns. Berkeley and Los Angeles: University of California Press, 1969.

CRAPANZANO, Vincent. "Estilos de interpretação e a retórica de categorias sociais". In: MAGGIE, Yvone. \& REZENDE, Claudia Barcellos. (Orgs). Raça Como Retórica: a construção da diferença. Rio de Janeiro: Civilização Brasileira, 2002.

FANON, Frantz. Black Skin, White Masks. New York: Grove Press, 1991.

GILROY, Paul. Atlântico Negro: modernidade e dupla consciência. São Paulo: Editora 34; Rio de Janeiro: Universidade Cândido Mendes, Centro de Estudos Afro-Asiáticos, 2001.

GILROY, Paul. Against Race: imagining political culture beyond the color line. Boston: Harvard University Press, 2000.

HALL, Stuart. "Quem precisa de identidade?". Identidade e diferença: a perspectiva dos estudos culturais. Petrópolis: Editora Vozes, 2003.

HALL, Stuart. "Identidade Cultural e Diáspora". Revista do Patrimônio Histórico, no. 24, 1998.

HALL, Stuart. "Identidade Cultural”. Fundação Memorial da América Latina. São Paulo. Coleção memo, 1997.

HALL, Stuart. "A Questão da Identidade Cultural”. In: Textos Didáticos. IFCH/UNICAMP, $n^{\circ} .18,1995$.

MONAGREDA, Johanna Katiuska. "A raça na construção de uma identidade política: alguns conceitos preliminares”. Mediações, Londrina. V. 21 nº. 2, p. 366-393, jul-dez, 2017.

MUNANGA, Kabengele. "Uma abordagem conceitual das noções de raça, racismo, identidade e etnia". Palestra proferida no $3^{\circ}$. Seminário Nacional Relações Raciais e Educação-PENESB-RJ, em 05-11-2003. Disponível em www.geledes.org.br. Capturado em 09-09-2020.

PINHO, Patrícia de Santana. Reinvenções da África na Bahia. São Paulo: Annablume, 2004.

RISÉRIO, Antônio. Carnaval Ijexá. Salvador: Corrupio, 1981.

SCOTT, Joan W. "O enigma da igualdade”. Estudos Feministas, Florianópolis, 13(1): 216, janeiro-abril /2005

WEBER, Max. "Relações Comunitárias Étnicas”. In: Economia e Sociedade. Brasília: Editora UNB, 1991.

Revista Educação e Ciências Sociais, Salvador, v.3, n.5, 2020. 